\title{
El empleo en la ciudad de México a fines del siglo XIX. Una discusión*
}

\author{
Hira de Gortari Rabiela
}

\section{A manera de Introducción}

El problema del empleo urbano es un asunto cuya importancia ya no se discute, en cambio, su análisis y la manera de acercarnos históricamente requiere plantearse hipótesis para las cuales es indispensable contar con una información adecuada.

El ensayo que a continuación se presenta, trata de seguir el uso de una fuente a la cual hasta ahora pocas veces se ha recurrido sistemáticamente y que puede servir para conocer más de cerca las formas de incorporación al empleo de ciertos sectores de la población.

Se escogió como escenario la ciudad del México porfirista, pues su economia interna estuvo sujeta a modificaciones que alteraron la estructura del empleo y que se registraron en alguna medida en la fuente que analizaremos a continuación.

Por lo anterior, el trabajo tiene dos objetivos. El primero es el de contribuir a esclarecer ciertas condiciones y requisitos indispensables para la incorporación al empleo de trabajadores y empleados en la ciudad de México entre finales del siglo pasado y principios del actual, asunto que forma parte de los innumerables problemas que concurren en el funcionamiento de un mercado de trabajo y que tiene interés porque nos acerca a su gestación y formación.

Mencionamos a estos últimos porque a pesar de la importancia per se se les ha ignorado, ya que la mayor parte de los estudios realizados se dedican casi exclusivamente a los grupos involucrados directamente en la producción, posición cada vez más insostenible. ${ }^{1}$

El asunto que planteo es arduo y complejo, por falta de información entre otras razones, en la medida que estamos delante de actores históricos que han dejado pocas trazas sobre su transcurrir cotidiano y en cambio predomina la que da cuenta de su actuación política e ideológica, contribuyendo a desarrollar investigaciones sobre todo acerca de la problemática política y su dirección.

El segundo objetivo consiste en mostrar las posibilidades y los límites de una fuente de información hasta hoy poco utilizada y que a mi entender nos da luces sobre un conjunto de hombres y mujeres relativamente amplio. 


\section{La fuente}

El utilizar en este ensayo una fuente de información poco explotada responde a preocupaciones manifiestas en la historiografía social contemporánea, interesada en escudriñar en conglomerados de la sociedad cada vez más vastos y para lo que es indispensable disponer de fuentes ad hoc.

Este interés ha abierto un horizonte novedoso en el conocimiento de grupos de mayores dimensiones, así como la utilización de materiales y documentos tales como los censos de población, donde los grandes números y sus variaciones en diferentes intervalos son un medio indispensable para estudios de conjunto.

Los censos nacionales llevados a cabo bajo el régimen de Porfirio Díaz se inician con el de 1895 y se continúan con el de 1900 y 1910 y para cualquier estudioso de la sociedad porfiriana son de consulta obligatoria ya que, a manera de fotografías intercaladas en el tiempo, proporcionan imágenes sucẹsivas de las diferentes categorías en las cuales fue clasificada la población.

Como no es el propósito de este trabajo extraer la información principal de los censos, no detallaré problemas como las dificultades que existen para compararlos entre sí; haré solamente hincapié en que si nos limitamos exclusivamente a la consulta de los censos, ciertas lagunas son prácticamente imposibles de cubrir. Concretamente, en los censos se registraron diferentes categorías profesionales y sus variaciones cuantitativas, pero no podemos profundizar más allá de las variaciones entre cada intervalo temporal y, si nuestra intención es conocer alguno de estos conglomerados con mayor detalle, es necesario recurrir a otros medios de información.

Una fuente que me parece añade datos importantes para el problema que me ocupa es la de las ofertas y demandas de empleo publicadas en el periódico El Imparcial, para lo cual hice una muestra a partir del año de 1898 y los primeros años del siglo actual, hasta $1908 .^{2}$

Sin embargo, es evidente que hay que hacer reparos. El primero es que, dadas sus características, la información incluye casi exclusivamente actividades que pueden catalogarse como comprendidas dentro de la producción no agrícola y en un sentido amplio, en la de los servicios.

Habria también que advertir que de ninguna manera pretendo cuantificarlas porque hasta anora no parece que esto sea posible, en la medida que por las propias características de la fuente, las ofertas y demandas publicadas no corresponden con el estado real del mercado de trabajo y más bien su utilidad radica en mostrar algunas características cualitativas y sus condiciones - mas no todas - previas a la contratación; es en este aspecto donde pienso que abre perspectivas que considero útiles.

Hay que tener presente que las ofertas de empleo se limitan generalmente al conocimiento de una población alfabeta: condición que deli- 
Sería un error - como decía - identificar la muestra con el mercado de trabajo, porque sin duda había otras formas de contratación más usuales y quizás más frecuentes, como el anuncio de vacantes en los centros de trabajo, los vínculos personales y comunicación oral, todas ellas imposibles de aprehender empíricamente.

En cuanto a la muestra, es notable el abultado número de casos del ramo de los servicios, a tal punto que los de la esfera de la producción parecen subrepresentados. Diferencia tan notable tampoco corresponde estrictamente a un comportamiento del mercado. Aunque si bien existen índices que podrían confirmar una tendencia a un mayor dinamismo en los servicios, traerlos a cuenta sería alejarnos del propósito de este trabajo. Al respecto y concretándonos a la información de que dispongo, parecería que la mayor parte de las posibles contrataciones en el sector productivo fabril, mas no así las circunscritas a las artes y oficios, se difundían como se menciona anteriormente.

Eso sí, debe quedar claro que la mayor parte de los anuncios de ofertas y demandas de emplẹo corresponden a los servicios, por lo que es una fuente particularmente rica para el conocimiento de este género de actividades tan importantes en una ciudad como México.

Anotaremos también la desproporción entre el gran número de ofertas y la menor cantidad de demandas de empleo; diferencia que se explica por una verdad de perogrullo, ya que los que buscan contratar trabajadores o empleados cuentan con los recursos para pagarlos y, claro está, disponen de los ingresos - muchos de ellos - como para hacer una inserción pagada; en cambio, los que buscan empleo no disponen de los medios para hacerlo, salvo excepciones.

Debo señalar que la información extraída puede ser un índice en algunos casos de categorías de trabajo que escaseaban, ya fuera porque se requiriesen en mayor número, por la novedad de la función para la cual se pensaban emplear o por el grado de calificación que dificultaba encontrar al personal idóneo. Cabe advertir, por último, que sabemos que se trata de posibles contrataciones y que no hay certeza de que efectivamente fueran definitivas. Una vez dicho esto, situémonos cronológica y temáticamente: ${ }^{3}$

\section{La situación}

Los últimos años del siglo XIX y algunos previos a la crisis de 19061907, se caracterizaron por un importante crecimiento económico en sectores vinculados tanto al mercado internacional como a mercados internos. Incrementos en la producción y la comercialización que contribuyeron a modificar la estructura socioeconómica de las regiones conectadas con dicho fenómeno. ${ }^{4}$

Las ciudades, por ejemplo, estuvieron entre los conglomerados más expuestos a la mudanza antes descrita y esto puede explicarse en parte 
porque alentaron la comercialización gracias al hecho de ser redes de distintas casas y matrices como las de financiamiento, maquinaria, etc., y a haberse afirmado como plazas comerciales de los mercados locales y regionales circundantes; contaban además en varias ocasiones con establecimientos productivos, principalmente de bienes de consumo que cubrían necesidades de sectores importantes de la población local y regional. En estos cambios, las nuevas comunicaciones fueron un medio que permitió estrechar aún más redes comerciales con el interior y exterior del país. Dentro de este contexto situemos a la ciudad de México. ${ }^{s}$

El escenario: la ciudad de México. La ciudad de México volvió durante estos años a ser la capital de la República con todas sus letras, pues si formalmente lo fue siempre, la compleja historia de una parte sustancial del siglo pasado puso en jaque el que fuera efectivamente reconocida como capital con propios y extraños.

Es en las tres últimas décadas del siglo XIX cuando se registra un fortalecimiento del poder federal, el cual coincide, no por azar, con la consolidación de la ciudad de México como capital del llamado pacto federal albergando a los principales depositarios del poder.

El nuevo sistema ferrocarrilero convierte a la capital en el centro rector y por tanto en paso obligado de las líneas más importantes, pues la orientación en su trazado obedeció a decisiones políticas y prácticas económicas que siguieron rutinas y tradiciones seculares que privilegiaban a la ciudad de México.

Es explicable entonces que el ser la capital política y el contar con una red de transportes moderna la convirtiera rápidamente en la plaza comercial más importante de la República y que aún cobrara mayor pujanza con la abolición en 1896 del sistema de alcabalas. ${ }^{6}$

Un cambio sustancial en las ciudades mexicanas a finales de siglo fue el incremento en su número de habitantes; ciudades como Mérida, Veracruz, Guadalajara y Monterrey tuvièron crecimientos demográficos amplios. La ciudad de México creció a un ritmo menor -en términos relativos - que las antes citadas, aunque debe recordarse que ya era y se mantuvo como la ciudad más poblada del país; así, en 1895 contaba con 330 mil habitantes y para 1910 alcanzaba un poco más de los 470 mil.

Las funciones que cumplía la ciudad de México junto con el aumento de su población contribuyeron a modificar en parte su fisonomía y dimensión debido a lo que hoy llamamos proceso de urbanización en el cual los gobernantes de la elite porfiriana impusieron con relativa facilidad sus intereses y gustos atrancesados. Se construyeron a un ritmo intenso calles y avenidas, edificios públicos y privados, así como casas-habitación más que ostentosas; se diseñó y puso en marcha una red de transporte urbano y suburbano y no faltaron obras públicas de grandes dimensiones con el objeto de procurar el alivio a los trastornos naturales que seguían acarreando a la comodidad y salud de sus habitantes el haher edificado la ciudad sohre un sistema lacustre 
éxito completo, pues, para lamento de los beneficiados por el progreso, una parte de la vieja faz de la ciudad registró pocos cambios, tanto en lo físico como en sus hábitos y costumbres. Confirma esto último el testimonio de los visitantes extranjeros, el cual quedó plasmado en algunas excelentes descripciones sobre la miseria y las pésimas condiciones de vida de los grandes núcleos de población, aunque no dejaban de quedar maravillados frente a la nueva ciudad, a la que calificaban a la par de las principales capitales europeas, pero sin dejar de contrastarla con los lugares donde todo parecía indicar se había detenido el tiempo y que no eran sino las deterioradas construcciones coloniales. ${ }^{7}$

Las principales actividades de la ciudad. En cuanto a las actividades troncales de la ciudad sobresalen dos ramas a las cuales me referiré: una, la de los lugares dedicados a la producción, como talleres y manufactureras, sin faltar las fábricas y aunque la mayor parte de las últimas estaban localizadas en las afueras, elaboraban en su mayoría artículos de consumo como alimentos, bebidas, textiles (hilados, tejidos y estampados), confección de ropa, tabaco, zapatos, etc. Bienes ligeros: curtidos, muebles, cerámica, papel, vidrio, productos químicos, trabajo de metales, partes de equipo de transporte, trabajos de imprenta, encuadernación, etcétera.

Respecto a la escala de operación, predominaban los talleres y manufactureras, pese a que para los años que analizamos, la concentración fabril del ramo tabacalero convirtió a la ciudad de México en la principal transformadora de este producto en el país.

Habría que añadir que la introducción de la energía eléctrica que se llevó a cabo en estos años, contribuyó a resolver muchas de las carencias e irregularidades en el aprovisionamiento de energía prevalecientes en la zona, posibilitando la creación y el desplazamiento al interior de la ciudad de establecimientos de mayores dimensiones. ${ }^{8}$

La otra rama era la de los servicios, donde no faltaba desde el pequeño comercio común y corriente que vendía distintas mercancías para el consumo y abasto de los habitantes capitalinos, hasta el comercio de amplia escala controlado por tiendas como El Palacio de Hierro, que seguían causando asombro por sus dimensiones y el estar oganizados en departamentos a la usanza francesa.

Junto con la fundación de grandes tiendas se dio paso a lo que podemos llamar servicios modernos, con los cuales se creó una infraestructura comercial, bancaria y de apoyo a la producción, como era el establecimiento de casas representantes de matrices de un sinnúmero

7 Secretaría de Economia. Dirección General de Estadística, Estadísticas sociales del Porfíriato, 1877-19J0, México, 1956, Censo general de la República Mexicana. verificado el 28 de octubre de 1900 , conforme a las Instrucciones de la Dirección General de Estadística a cargo de D. Antonio Peñafiel, México, Secretaria de Fomento, Oficina Tipográfica de la Secretaría de Fomento, 1900; véanse también los de los años de 1895 y 1910.

${ }^{8}$ Las obras más recomendables son: Fernando Rosenzweig, "La industria" en Daniel Cosío Villegas. Historia Moderna de México. El Porfiriato. Vida Económica. México, Edi- 
de firmas extranjeras, indispensables para las nuevas características de la economía nacional. ${ }^{9}$

\section{El problema}

Como desde el principio del trabajo señalé, de ninguna manera pretendo explicar el mercado de trabajo de la ciudad de México, pero sí señalar algunos problemas referentes a las condiciones y tipos de contratación para lo cual me parece indispensable hacer algunas consideraciones.

En la economía mexicana de finales del siglo pasado, la mercantilización de la producción y los servicios cobraron nuevos ímpetus que hicieron necesaria e indispensable la incorporación de un número de trabajadores y empleados cada vez más amplio.

Como sabemos, el crecimiento de la economía no fue un proceso homogéneo que abarcara al país en su conjunto, sino privilegio de las regiones que disponían de los recursos naturales aprovechables y que, al igual que las riquezas naturales; la mano de obra, condición sine qua non para la expansión económica, estaba irregularmente distribuida en el territorio. Caracterizábase entonces la población por profundos contrastes que se remontan a periodos anteriores a la colonia, entre porciones densamente pobladas y otras escasamente habitadas, situación que dificultaba los proyectos de explotación de regiones con abundancia de recursos pero con escasa mano de obra. ${ }^{10}$

Vista desde la perspectiva anterior y tomando en cuenta su posición geográfica en la porción central del país, la ciudad de México estaba situada en una zona de abundancia demográfica, donde vivía cerca de la mitad de la población nacional y así fue descrita en 1892 por Matías Romero como “...la región (donde) los trabajadores son tan abundantes que exceden con mucho a la demanda. Los jornales son por consiguiente bajos y el sistema de peonaje existe en muy escasas proporciones"."1

Esto se tradujo en la salida de numerosos contingentes de migrantes a distintas partes de la República e incluso más allá de la frontera norte. La capital fue una excepción pues no sólo no sufrió merma en sus habitantes, sino que éstos aumentaron en forma considerable.

La migración a la ciudad de México. Los principales grupos migratorios de origen interno que arribaron a la ciudad provenían en su inmensa mayoría de los estados cercanos, tales como el Estado de México, Hidalgo, Puebla, Querétaro y Guanajuato; en 1895 el $43 \%$ de sus habitantes no había nacido en la ciudad, ni en el Distrito Federal; porcentaje que para 1910 representaba el $49 \%$ y que en números absolutos el primero significaba 142 mil fuereños y que al terminar la primera década del siglo rebasaban las 226 mil personas. ${ }^{12}$ 
En cuanto a los migrantes de origen extranjero, su monto no es en forma alguna comparable con los nacionales, aunque fue decisiva su importancia cualitativa en determinadas actividades, sobre todo por su grado de calificación profesional. En 1900 se censaron a 12 mil personas como extranjeras y en 1910 a un poco más de 22 mil; cifra está última que representa la quinta parte de los residentes extranjeros que vivían en el país. ${ }^{13}$

La ciudad de México: un centro de empleo. Como señalábamos anteriormente, las corrientes migratorias contribuyeron al crecimiento demográfico de la ciudad, pero también a ampliar el número de hombres y mujeres que potencialmente podían incorporarse a la economía urbana, pues presumiblemente muchos de los migrantes tenían las edades adecuadas para incorporarse a algún trabajo.

Dicha posibilidad se corrobora con la fuente hemerográfica que hemos utilizado, dado que era factible - según encontramos - contratar distintos tipos de trabajadores y empleados para la propia ciudad. Asimismo, y esto es sumamente interesante, en la capital también se buscaban personas para satisfacer necesidades de empleo de diversas poblaciones del Distrito Federal y aun de varios estados de la República. Pasemos a examinarlos.

Para el interior. Es conocido cómo, durante los años que analizamos, se reclutaba mano de obra forzosa para las regiones donde escaseaba, pues como escribía Romero, en las costas "de ambos océanos y algunas otras localidades bajas, situadas en el interior del país (están) casi (deshabitadas y) los trabajadores son alli por lo mismo muy escasos..." 14

En la ciudad, los enganchadores encontraban un magnifico centro de reclutamiento, pues mediante engaños, como el que anotamos a continuación, conseguían contingentes de trabajadores. El reportero de $E l$ Imparcial escribía refiriendo cómo había sido enganchado un grupo de trabajadores:

“...hacía dos días esa gente había sido reclutada para trabajar según se dijo, en la capital, dándoles tres pesos de enganche. Al día siguiente se les dijo, que como aquí ya no se necesitaban sus servicios, iban a ser enviados a Cuautitlán, donde trabajarían durante veinte días para desquitar el dinero que habían recibido, y como algunos se negaron a partir, se les retuvo en el... mesón.

Finalmente, ya al salir, supieron que iban a ser enviados al Valle Nacional, y para mayor abuso, a las mujeres se les había recogido cuanto dinero les quedaba de los tres pesos que antes se les dieran, y los objetos que habían comprado."15

La contratatación de trabajadores para el interior del país no fue exclusivamente de enganchados, también en la capital se podían obtener contrataciones voluntarias para aquellos de los capitalinos cu- 
yas habilidades podían interesar en otras partes de la República. Así, encontramos ofertas de empleo para diversas entidades del país, y no exclusivamente de las cercanas a la ciudad, pues localizamos de Durango, Guanajuato, San Luis Potosí, además de Hidalgo, el Estado de México, etc. En cuanto a los lugares de trabajo sobresalen las minas, las haciendas y ranchos, empresas fabriles y talleres. ${ }^{16}$

Para las afueras de la ciudad. En la capital, según nuestra muestra, se contrataba personal para laborar en las principales municipalidades en que estaba dividido el Distrito Federal; había ofertas de trabajo para Tacubaya, Tlalpan, San Angel, Mixcoac, Guadalupe Hidalgo; Tacubaya ocupa sin duda un lugar destacado y esto parece obedecer a que era la cabecera más poblada del D. F. ${ }^{17}$

Estas relaciones entre la capital y las municipalidades contribuyen a confirmar su grado de intensidad y dejan ver cómo la ciudad de México consolidaba, paso a paso, su posición prominente, rodeada de una serie de poblaciones menores, dependientes a manera de planetas y satélites alrededor del sol.

Para la ciudad. En cuanto a los resultados de la muestra para la propia ciudad, el número de posibles contratataciones obviamente crece enormemente si se compara con los anteriores.

El disponer de una mayor cantidad de anuncios permite - con cierta precaución- elaborar algunas tendencias que se dibujan y que me parece interesante describir. Como se señalaba inicialmente, gracias a la fuente utilizada es posible en cierta medida adentrarnos en la demanda del mercado por determinadas profesiones y oficios, cuya actividad era sobre todo solicitada más que ofrecida por las siguientes razones: porque se necesitaba contratar un mayor número de personas; porque se deseaba llevar a cabo trabajos novedosos o de reciente implantación, o por requerir un cierto grado de calificación.

Las razones antes expuestas orientan y marcan tendencias en cuanto a la incorporación al trabajo y responden a las características de la economía local y regional; así, había un conjunto importante de solicitudes para actividades en la producción y en los servicios que hacen importantes cambios. Aunque existía también un numeroso conglomerado de ocupaciones arraigadas de largo tiempo atrás. Revisemos algunas de las tendencias principales.

Uno de los rasgos más notorios que se perfilan de la muestra, son los ofrecimientos de empleo a especialidades y calificaciones que presuponen formas de trabajo recién incorporadas, o aquéllas que se extienden

16 Podemos citar como un caso ilustrativo el siguiente: "Se solicita un ingeniero o minero para la dirección de una mina en el estado de Guanajuato. Con práctica, experiencias y referencias", idem, 5 de enero de 1908; o "Médico. Para hacienda en el Estado de Veracruz", idem, 7 de noviembre de 1908. "Farmacéutico. Que sea titulado y que hable inglés. Mineral del Oro. Estado de México", ídem, 13 de diciembre de 1908. Veáse también Asiasin, División municipal de la república mexicana, México, Oficina Tipográfica de la 
con relativa rapidez y que en diversos casos suponían un grado de calificación solicitado en forma explícita. En los servicios, que como hemos mencionado se expandieron considerablemente, encontramos ejemplos sugestivos: las solicitudes para puestos de dirección, administración y supervisión, llámense directores, gerentes, administradores o encargados, están en nuestra muestra; se piden para diferentes centros de trabajo como fábricas, molinos, haciendas, talleres, hoteles, restaurantes, etc.; un cierto número de ofertas no se limitan a la ciudad, pues provienen de las afueras y del interior del país; es frecuente encontrar quienes solicitan personas aptas, por ejemplo ingenieros, para dirigir y administrar yacimientos mineros. ${ }^{18}$

Entre las profesiones más estrechamente vinculadas a las labores de control de cualquier empresa o negocio, estaban los tenedores de libros, actividad que cobraba importancia, pues tanto las ofertas como los propios tenedores de libros atestiguaban lo indispensable de su trabajo, ya que se daba el caso de que ellos mismos ofrecieran horas, mediodía tardes, etc., para realizar el trabajo ahí donde se solicitara. Requerían sus servicios casas comerciales, almacenes, despachos, haciendas, etc. Es interesante mencionar que para este género de contables, se pedían en ocasiones conocimientos adicionales como el conocimiento de idiomas, o el que supieran escribir a máquina, instrumento que paulatinamente se difundia en el medio profesional. ${ }^{19}$

Los empleados de oficina, comercios y despachos, junto con los mecanógrafos y taquígrafos fueron convirtiéndose en un conglomerado que en la medida que crecía la cantidad de oficinas y negocios, aumentaban las solicitudes interesadas en sus servicios: el que bufetes, notarías, casas de diferentes géneros comerciales, cajones de ropa, haciendas, periódicos, etc., necesitaran sus habilidades, como se aprecia en la muestra, nos indica que la gestión de administración y venta precisaba un mayor número de personas, pero también personal capacitado; esto último, por cierto, estaba compuesto en parte por mujeres. ${ }^{20}$

En la comercialización y distribución, los agentes de ventas tuvieron un papel destacado; en los abundantes casos que recolectamos, eran muy solicitados pues se encargaban como representantes de dar a conocer los productos y marcas, arreglar tratos e intercambios, surtir a las plazas cercanas como a las del interior. Se necesitaban para distribuir y vender los más diversos productos y servicios; jabones, semillas, dulces, vinos y licores, cerveza, artículos de fotografía, máquinas de escribir, toldos, cortinas, tapones, publicaciones, seguros de vida, artículos de papelería, bicicletas, etc., e incluso ya a principios de siglo se buscaba un agente encargado de la venta de automóviles. ${ }^{21}$

Un grupo de menores dimensiones que aparece en nuestra fuente,

18 "Director. Para dirigir una fábrica de alcoholes y granos." Idem, 1 de julio 1901. "Administrador. Se ofrece para fincas o haciendas", idem, $1^{\circ}$ de noviembre de 1907.

19 "Tenedor de libros nara casa de comercio Dehe saher eccrihir en mánuina" idom 1 
pero no por eso menos significativo, estaba compuesto por los electricistas y mecánicos o la combinación de ambos, cuyas funciones gracias a la electrificación y a una mayor tecnificación, se fueron haciendo indispensables en distintos géneros de actividad como plantas eléctricas, ingenios, lavanderías, haciendas, talleres mecánicos y de automóviles, etcétera.

Precisamente entre los casos recolectados que son signo de cambio en las costumbres y las diversas ofertas de trabajo, encontramos anuncios para los llamados "chauffeurs", necesarios después de la introducción del automóvil: Y en este mismo género de novedades, los empleados para el cinematógrafo. Actividades éstas que no se limitaban a la ciudad, pues eran requeridas tanto en el Distrito Federal como en el interior. ${ }^{22}$

Hasta ahora hemos prestado atención a las solicitudes de empleo que indican cambios en los servicios, así como en el funcionamiento de la economia urbana y regional; pero, como advertíamos, a través de la muestra, es posible considerar también amplios conjuntos de ocupaciones cuya historia data de largo tiempo atrás. Al respecto nos referiremos exclusivamente al servicio doméstico.

En el material recolectado sobresalen por su cantidad las ofertas de empleo para esta categoría de empleados. Eran un denso conglomerado social de la capital porfiriana el cual, según las evidencias, continuaba ensanchándose.

Por lo que en los ofrecimientos de empleo para domésticos no sólo llama la atención su abundancia, sino también la variedad que de estos había; un sector social tan vasto sólo encuentra su explicación en tradiciones históricas de la propia sociedad, las cuales como patrón de conducta, sobre todo de la elite, imitado por otros grupos fincan como un símbolo objetivo de su riqueza y poder el disponer de sirvientes y entre mayor número mejor. Para esto era indispensable, no olvidemos, el contar con un nutrido conjunto de hombres y mujeres con escasa calificación, cuyos servicios fueran en general escasamente remunerados.

Por las razones anteriores se encuentran peticiones de mayordomos, institutrices, amas de llaves, lacayos, cocineros, asistentes, cuidadores de niños con distintos nombres comó eran el de nodriza, dama de compañía, nana, pilmama; asi también se solicitan lavanderas, mozos, sirvientes, porteros, recamareras, criados, jardineros, costureras domésticas; es otro rasgo característico el que en su inmensa mayoría fueran mujeres. ${ }^{23}$

Es interesante mencionar asimismo los refinamientos de algunas solicitudes pues denotan actitudes y comportamientos profundamente enraizados en la conducta y hábitos de muchos núcleos de la sociedad mexicana, como el precisar el carácter étnico del futuro empleado, 
distinguiendo entre indios y blancos no necesariamente con fines discriminatorios pero sí distintivos. Así sorprende el que se buscara expresamente nodrizas indigenas, como también el que se procurasen empleados domésticos de origen extranjero que daban prestigio, y los cuales, según se aprecia en la muestra, entendidos de que sus servicios eran apreciados, ofrecían ellos mismos sus habilidades. ${ }^{24}$

En el campo de los trabajadores en talleres y manufactureras, la fuente utilizada no fue tan esclarecedora, en la medida que registra un menor número de casos: podríamos conjeturar que no era el medio preferente para la contratación ya que existían otras formas de hacerlo, a las cuales hemos hecho alusión inicialmente.

Sin embargo localicé algunas formas de empleo en particular para la rama fabril y de la construcción. Se trata de establecimientos de escala distinta como talleres y fábricas y en las cuales se hace explícita la jerarquía del trabajador al solicitar maestros, oficiales, sobrestantes, ayudantes, meritorios, aprendices, ${ }^{25}$ además de precisarse con claridad el oficio, tales como la herrería, la carpintería, y otros como barnizadores ebanistas, talladores, torneros, mecánicos. ${ }^{26}$

En los anuncios de empleo destacan las ofertas para los trabajos de confección de ropa y artículos de vestir; sin embargo no localicé por el contrario ninguna solicitud referente a las fábricas de hilados y tejidos. que se encontraban en la ciudad o en las afueras.

Las solicitudes para la industria del vestido son numerosas y hacen patente la variedad de los trabajos que se llevan a cabo en esta actividad, así. como el uso intensivo de mano de obra predominantemente del sexo femenino, aunque no se excluía a los varones, corpiñeras, bordadoras, enagüeras, camiseras, corbateras, falderas, pantaloneras y sastres que tenían demanda. ${ }^{27}$ Estos oficios eran en general de escasa calificación, aunque en ciertos casos no estaban exentos de jerarquías, por lo cual se especificaba en las demandas la necesidad de oficiales sombrereras, oficiales empuntadoras, ayudantes de corpiñeras, ayudantes de sastres, oficiales de sastrería. ${ }^{28}$

Por su cuantía en las ofertas sobresalen las solicitudes para contratar costureras para fábricas y tiendas de ropa cuyo requisito era que supieran coser a mano y a máquina. Entre las costureras es frecuente

24 "Lacayo de color blanco." 18 agosto 1901. "Nodriza. Indigena o morena." 8 enero 1908. "Institutriz. Americana. Desea posición de gobernante de una niña o como dama de compañía." 30 junio 1898. "Nodriza. Española. Leche fresca, desea criar en casa buena." 22 noviembre 1907.

25 "Oficiales de herreria. Para fábrica de camas de hierro y latón." 28 noviembre 1907. "Maestro afilador. Para taller. Debe saber trabajos mecánicos." 21 marzo 1898. "Sobrestantes de carpintería. Para taller de carpinteria." 17 noviembre 1907. "Maestro laminador. Para taller. Para hacer toda clase de trabajos en lámina." 10 septiembre 1901.

${ }_{26}$ "Carpinteros. Varios. En edificio nuevo. Trabajo seguro." 17 noviembre 1907 "Barnizadores. Varios." 19 noviembre 1907. "Hojalateros. Fábrica de incubadoras." 21 de mayo 1898. "Talladores. Para los talleres de la Sociedad Artística." 4 enero 1908. "Ebanista nara muebles " 20 diciemhre 1907 
encontrar que realizaban su labor a domicilio y a destajo, características difíciles de discernir por este tipo de información que precisaba: "Costurera. Para hacer el trabajo en su domicilio" o "Trabajo para fuera o por pieza", o con mayor exactitud se pedía para "...camisas y trajes de niño" o "Bordadoras de calcetines. Trabajo a domicilio." ${ }^{2}$

\section{A manera de conclusión}

La problemática analizada en el trabajo está lejos de agotarse, pues un sinnúmero de interrogantes quedan aún sin respuesta. Pensamos que el camino utilizado abre perspectivas y permite esclarecer algunas de las relaciones entre la estructura económica, los movimientos de población y su incorporación al trabajo. Estamos cada vez más convencidos que para profundizar en el mundo del trabajo es indispensable conocer el funcionamiento del mercado. Mucho se ha discutido la formación ideológica de diversos núcleos sociales, labor importante, pero se ha hecho caso omiso de sus condicionantes estructurales.

Es entonces prioritario estudiar los coinponentes del mercado de trabajo y no solamente vistos como un problema teórico, sino en contextos históricos específicos; pensamos que muchas de las claves de las actitudes, movimientos y expresiones sociales de una sociedad responden al estado del mercado de trabajo. 